\title{
BMJ Open Competing needs: a qualitative study of cervical cancer screening attendance among HPV-positive women in Tanzania
}

\author{
Ditte Søndergaard Linde, ${ }^{1,2,3}$ Vibeke Rasch, ${ }^{1,2}$ Julius D Mwaiselage, ${ }^{4}$ \\ Tine M Gammeltoft ${ }^{5}$
}

To cite: Linde DS,

Rasch V, Mwaiselage JD, et al. Competing needs: a qualitative study of cervical cancer screening attendance among HPV-positive women in Tanzania. BMJ Open 2019;9:e024011. doi:10.1136/ bmjopen-2018-024011

- Prepublication history and additional material for this paper are available online. To view these files, please visit the journal online (http://dx.doi. org/10.1136/bmjopen-2018024011).

Received 14 May 2018 Revised 21 November 2018 Accepted 29 November 2018

Check for updates

(C) Author(s) (or their employer(s)) 2019. Re-use permitted under CC BY-NC. No commercial re-use. See rights and permissions. Published by BMJ.

${ }^{1}$ Department of Obstetrics and Gynaecology, Odense University Hospital, Odense, Denmark ${ }^{2}$ Institute of Clinical Research, University of Southern Denmark, Odense, Denmark

${ }^{3}$ OPEN, Odense Patient Data Explorative Network, Odense University Hospital, Odense,

Denmark

${ }^{4}$ Department for Cancer Prevention Services, Ocean Road Cancer Institute, Dar es Salaam, Tanzania

${ }^{5}$ Department of Anthropology, University of Copenhagen, Copenhagen, Denmark

Correspondence to Ditte Søndergaard Linde; dsondergaard@health.sdu.dk

\section{ABSTRACT}

Objectives The aim of this study was to understand causes of attendance and non-attendance to a follow-up cervical cancer screening among human papillomavirus (HPV)-positive women.

Design Semistructured, individual interviews with HPVpositive women and cervical cancer screening nurses. The interview guide and initial data analysis were guided by existing health behaviour theories. However, as the theories limited the potential of the data material, a grounded theory framework guided the final data analysis. Setting Interviews were conducted in Dar es Salaam, Tanzania, at Ocean Road Cancer Institute (ORCI) or in the homes of screening clients.

Participants 15 interviews were conducted with women who had tested HPV-positive during a patient-initiated screening and been appointed for a follow-up screening 14 months later. Nine women had not attended the followup appointment, four had delayed attendance and two had attended on the scheduled date. Further, individual interviews were conducted with the two nurses working at ORCl's screening clinic.

Results Perceived benefits for attending a patientinitiated screening include treatment of gynaecological symptoms and prevention of disease. The key perceived benefit of a health provider-initiated follow-up screening is prevention, which is challenged by the circumstance that it is seen by women as having merely potential benefit and therefore can be postponed when competing needs are present. Perceived challenges for screening attendance include emotional costs, in the form of fear of the disease, fear of the gynaecological examination as well as direct and indirect economic costs, such as transportation costs, lost income and waiting time.

Conclusion Cervical cancer screening is one among many tasks that women living in a low-income setting must attend to. Since health provider-initiated followup screening is seen as having only potential benefit, attendance can be postponed when competing needs exist.

Trial registration number NCT02509702.

\section{INTRODUCTION}

When walking into the cervical cancer screening clinic at Ocean Road Cancer Institute (ORCI) in

\section{Strengths and limitations of this study}

This is the first qualitative study in Africa that elucidates what motivates and prevents HPV-positive women from returning to a health-provider initiated follow-up cervical cancer screening.

- Based on our findings, we have developed a theoretical model for perceived costs and benefits of screening attendance, which potentially can be generalised to other screening scenarios and help understand screening behaviour in a broader perspective.

- Recruitment for this study was difficult and eligible participants included both women who had attended and not attended a follow-up screening. A more nuanced view may have appeared if participants had been limited to only one of these groups.

Dar es Salaam, Tanzania, it is evident that cervical cancer is a tremendous health issue. The line of women in the shaded waiting area is long and starts early every morning Monday-Thursday in order for women to receive one of the 25 unscheduled screening appointments. Twenty-five is the number of clients the two screening nurses can attend to each day apart from the screenings with clients that have been scheduled for a follow-up appointment. If a woman arrives late and misses one of the appointment numbers, she has to return another day (field note, first author).

East Africa is the region of the world that has the highest incidence rate (42.7 per 100.00 women) and mortality rate (27.6 per 100.000 women) of cervical cancer. ${ }^{1}$ The disease is a major public health issue in Tanzania, and with an incidence and mortality rate of 54.0 and 32.4 per 100.000 women, respectively, the burden of disease exceeds the regional average. ${ }^{2}$ The high prevalence of human papillomavirus (HPV) $(20 \%)^{34}$ and limited screening options are contributing factors to the cervical cancer burden in Tanzania. ${ }^{356}$ 
Cervical cancer screening is free of charge in Tanzania, and the standard is patient-initiated screening, which involves a gynaecological examination with visual inspection of the cervix after application of acetic acid (VIA) or lugol's iodine. However, rapid HPV DNA testing either through provider-based or self-sample tests ${ }^{36-8}$ is currently being tested as alternative screening methods. ${ }^{9}$ If a woman tests HPV-positive, she will be asked to return for a health provider-initiated follow-up screening. If diagnosed with cervical cancer, she will be treated according to the National Cervical Cancer Service Delivery Guidelines. This involves a biopsy and referral for treatment at the oncology clinic at ORCI, which is free of charge.

Effective screening programmes are key elements to overcoming the burden of disease in Africa, and a number of studies have investigated screening uptake barriers and determinants in Africa. Generally, studies show that the uptake of screening programmes is limited $(10 \%-29 \%)^{610-13}$ and associated with a complex set of individual, social and structural factors, for example, husband's approval, ${ }^{11} 1415$ distance to clinic, ${ }^{11} 1316$ gender of health professional, ${ }^{10}$ financial constraints, prioritising more contending needs when feeling healthy ${ }^{17}$ and fear of results, discrimination, pain or embarassment. ${ }^{711} 13-17$ The literature on follow-up after screening is limited. Two studies from South Africa address non-attendance for a scheduled follow-up visit ${ }^{18}$ and experiences with the referral pathway ${ }^{19}$ after having an abnormal pap smear, and one study from Nigeria, concern non-attendance for a scheduled follow-up visit after testing VIA-positive. ${ }^{20}$ The studies found that only $47 \%^{18}$ and $53 \%{ }^{18}$ returned for their follow-up appointments, and that the main reasons for non-attendance were time constraints and transportation costs. ${ }^{20}$ Further, women reported that having a gynaecological symptom was the most common reason for having a Pap smear while negative community opinions, fear of having an HIV test and low encouragement from peers were potential access barriers. ${ }^{19}$ To our knowledge, no studies have explored African women's experience with testing HPV-positive and reasons why health provider-initiated follow-up screenings may be defaulted among this group of women. It is important to understand the views of these women in order to make future screening programmes that involve HPV-testing more effective.

\section{Study context and objectives}

This paper is based on a qualitative study embedded in a randomised trial called Connected2Care (NCT02509702). The trial aims to assess the effect of short message service (SMS) on attendance at a health-provider initiated cervical cancer follow-up screening among women, who have tested HPV-positive during a patient-initiated screening. Both the patient-initiated and health provider-initiated screening entailed a gynaecological examination. The trial started in 2015 and is to finish in 2018. The study protocol is published elsewhere. ${ }^{9}$

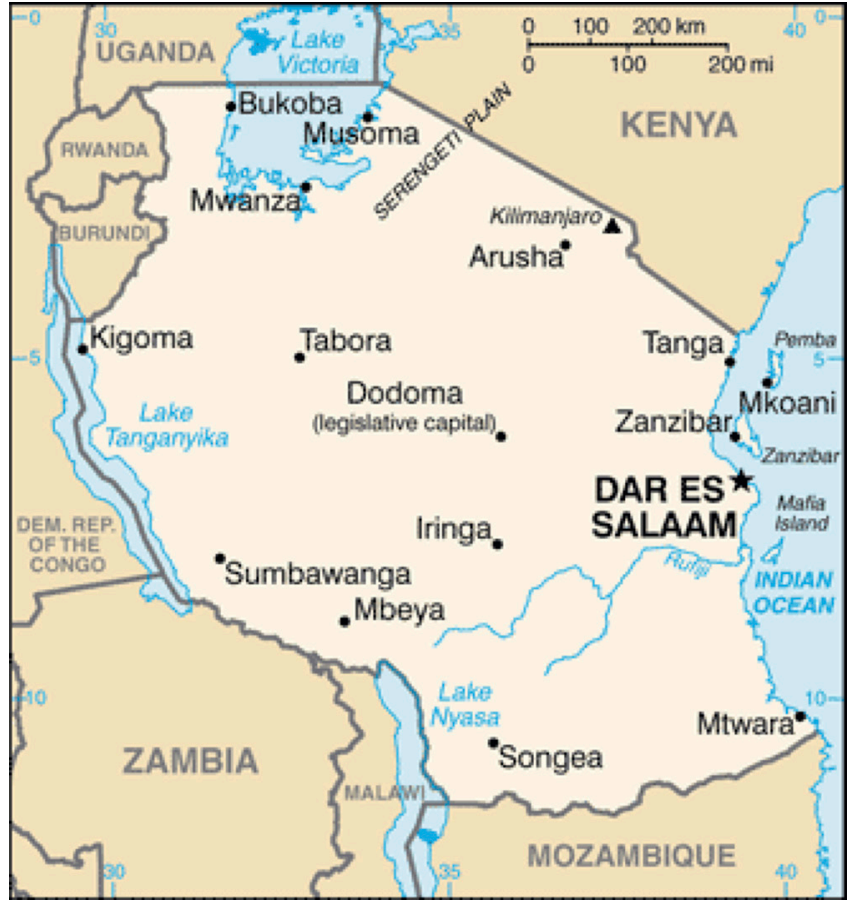

Figure 1 Map of Tanzania ${ }^{32}$ showing location of Dar es Salaam.

The qualitative study had two aims: (1) to understand reasons for (non)attendance to a health provider-initiated follow-up screening among HPV-positive women and (2) how these women perceive the SMS intervention. This paper focuses on the first objective and elucidates what motivates or prevents HPV-positive women from returning for a follow-up screening. The results of the second qualitative objective will be reported elsewhere.

\section{METHODS}

\section{Study site and sampling}

This study was conducted in July 2017 in Dar es Salaam, Tanzania (figure 1). Participants were purposively sampled and consisted of cervical cancer screening nurses working at ORCI and of women who live in the Region of Dar es Salaam, who had tested HPV-positive during a patient-initiated screening. Screening clients were eligible for interviews if they were HPV-positive, been scheduled for a 14 months follow-up appointment, were randomised to receive SMSs, and had either attended or missed the follow-up appointment. Eligible women were approached over phone in a consecutive order starting with those who had not attended their follow-up appointment to those that had delayed attendance and those who attended at the scheduled appointment date. All nurses working at the screening clinic were eligible for interviews and approached in person.

\section{Data collection}

A total 31 HPV-positive women were approached for interviews, and 15 individual semistructured interviews were conducted; nine women had not attended this appointment, four had delayed attendance and two had attended 
on the scheduled appointment date. The first author, who is female and had experience with qualitative data collection and analysis, interviewed all participants. Data collection stopped once data were saturated. All interviews were done in Kiswahili with simultaneous English translation. The translator was a female social worker from ORCI who was briefed about the study objectives prior to interviews. A total of three nurses were eligible for interviews; however, one was on maternity leave during the data collection period. Therefore, two individual interviews were conducted in English with screening nurses. All participants were given a bar of soap as a gift of gratitude.

Interviews were conducted in the women's homes or in a private room at ORCI with the location being based on the preference of the participant. When interviews were conducted at ORCI, transport costs were refunded. The interviews took place between 09:00 and 17:00 hours and lasted 21-54 min with an average of $36 \mathrm{~min}$. No other persons were present except the primary investigator, the translator and the participant. All interviews were audiotaped and later transcribed verbatim by a professional Tanzanian transcriber specialised in language studies, who also served as validator of the translation. Transcripts showed that minor translation errors occurred 15 times and the correct translation was written in the transcript. Written field notes supplemented the data, and each interview was debriefed once finished.

The final interview guide consisted of 30 questions (online supplementary file 1) and was inspired by other qualitative studies within the field of mobile health. ${ }^{2122}$ It was pretested in the winter, 2015 and spring, 2016 during a pilot study conducted in Bagamoyo, Pwani Region, which is $50 \mathrm{~km}$ from Region of Dar es Salaam. The guide was slightly modified during the first interviews in July 2017. Sociodemographic characteristics for each client were derived from a questionnaire that had been filled out during their initial screening.

\section{Theoretical framework}

The data collection tool was guided by the Healthcare Access Barrier (HCAB) model, ${ }^{23}$ the theory of planned behaviour ${ }^{24}$ and the technology acceptance model. ${ }^{25}$ The HCAB model also guided the initial coding and data analysis; however, as analysis progressed, it was apparent that the model limited the potential of the material. Therefore, Grounded Theory guided the further analysis where codes and theory were constructed based on the material. ${ }^{26}$ This enabled the analysis to stay close to the women's own experiences of the factors that motivated or prevented them from attending screening.

\section{Data analysis}

NVivo 11 (www.qsrinternational.com) was used for data analysis. A content analysis was conducted and data was coded into central themes by the use of a coding frame. ${ }^{27} 28$ The coding frame was developed in a two-step process. First, all data were coded in a combined inductive-deductive manner where central themes were deducted from the above-mentioned health theories and supplemented by inductive categories that arose from the transcripts. One researcher read through and coded all transcripts in this step. To test the reliability of the coding, a second peer researcher who was not familiar with the research field coded approximately $20 \%$ of the transcripts. The double coding process showed that the coding frame was promising; however, it led to a revision of some codes and subsequently to a consideration whether the coding frame was limited by the guiding theories. Consequently, data were recoded with a modified coding frame that only contained inductive categories that arose from the data (table 1).

At the end of the coding process, each transcript ID was replaced by a pseudonym and the top 17 names for Tanzanian women were used. $^{29}$ To avoid the translation link, 'she' was replaced with 'I' in the transcripts. The study was reported according to the Standards for reporting qualitative research guidelines. ${ }^{30}$

\section{Patient and public involvement}

Clients were not involved in the design or recruitment of the study. However, study participants were contacted and offered to comment on the final data analysis.

\section{Ethical considerations}

Ethical clearance for the overall Comprehensive Cervical Cancer Prevention in Tanzania (CONCEPT) study (online supplementary file 2), of which Connected2Care is a substudy,

Table 1 Elements of final coding frame

\begin{tabular}{|c|c|c|c|c|}
\hline Primary category & First subcategory & $\begin{array}{l}\text { Secondary } \\
\text { subcategory }\end{array}$ & $\begin{array}{l}\text { Third } \\
\text { subcategory }\end{array}$ & Fourth subcategory \\
\hline \multirow[t]{4}{*}{ Perceived costs } & Economic & Direct & Work & - \\
\hline & & Indirect & Time & Accessibility \\
\hline & & & & Family obligations \\
\hline & & Disease & - & - \\
\hline \multirow[t]{2}{*}{ Perceived benefits } & Symptoms & - & - & - \\
\hline & Prevention & - & - & - \\
\hline
\end{tabular}


was obtained from the National Institute for Medical Research in Tanzania, reference number NIMR/HQ/R.8a/ Vol. IX/1955. Informed consent was read to all participants (online supplementary file 3) and everyone consented and signed the consent form prior to data collection starting.

\section{FINDINGS}

\section{Characteristics of participants}

The mean age for the screening clients was 38.6 years and the majority had finished primary education $(67 \%)$ and were monogamously married $(67 \%)$. Sixty per cent were Muslim, 33\% were Christian and 1 did not disclose her religion. Further, $67 \%$ were HIV-negative, and $33 \%$ were HIV-positive. Eighty per cent had not been screened prior to the screening where they tested HPV-positive (table 2).

\section{The context of screening clients}

The data collection mirrors the complex context that defines the daily lives of Tanzanian women. This context needs to be taken into account when wanting to understand reasoning for screening behaviour.

Fifteen out of $31(48 \%)$ approached women accepted to participate in the interviews. Reasons for non-participation were: travelling outside Dar es Salaam $(n=5)$, work obligations $(n=3)$, husband had recently died $(n=2)$, woman had died $(n=2)$, woman did not wish to participate $(n=2)$, woman had developed cancer $(n=1)$, and woman was on maternity leave $(n=1)$. Moreover, six women did not pick up when calling to invite them into the study.

\section{Perceived benefits of screening}

During the interviews, the benefits of attending screening were discussed. Two women could not explain why they had attended screening, five said it was because of health preventive reasons. Eight stated it was due to symptoms they wanted to be examined for.

\section{Treatment of symptoms}

Women mainly described their reasons for going for the patient-initiated screening as the majority had not returned for the health provider-initiated follow-up screening. Most stated that they went in the first place due to gynaecological symptoms, which worried them. However, these were not necessarily related to oncogenic HPV. Grace said that she had a ' $[\ldots]$ certain kind of discharge from the vagina' (Grace) while Mary described that, 'I was itchy in my private parts' (Mary). Editha had the following reasoning,

My legs used to be numb, and I went to several hospitals and bought drugs from pharmacies for almost a year without noticing any improvements. At one point, I went to a hospital [...] and the doctor (asked) [...] if I bleed during sexual intercourse to which I answered yes [...]. At that point, the doctor advised me that I should go for cervical cancer screening. (Editha)

\begin{tabular}{|c|c|}
\hline Characteristics & $\mathbf{N}(\%)$ \\
\hline \multicolumn{2}{|l|}{ Age } \\
\hline Mean & 38.6 \\
\hline Min. & 27 \\
\hline Max & 55 \\
\hline \multicolumn{2}{|l|}{ Educational level } \\
\hline Primary (standard 5-7) & $10(66 \%)$ \\
\hline Lower secondary (form 1-4) & $3(20 \%)$ \\
\hline Upper secondary (form 5-7) & $1(7 \%)$ \\
\hline University/College & $1(7 \%)$ \\
\hline \multicolumn{2}{|l|}{ Marital status } \\
\hline Married monogamous & $10(66 \%)$ \\
\hline Married polygamous & $2(13 \%)$ \\
\hline Divorced/Widow & $2(13 \%)$ \\
\hline Single & $1(7 \%)$ \\
\hline \multicolumn{2}{|l|}{ Living conditions } \\
\hline Husband/cohabiter & $12(80 \%)$ \\
\hline Other relatives & $2(13 \%)$ \\
\hline Nobody & $1(7 \%)$ \\
\hline \multicolumn{2}{|l|}{ Religion } \\
\hline Muslim & $9(60 \%)$ \\
\hline Christian & $5(33 \%)$ \\
\hline Missing & $1(7 \%)$ \\
\hline \multicolumn{2}{|l|}{ HIV } \\
\hline Negative & $10(67 \%)$ \\
\hline Positive & $5(33 \%)$ \\
\hline \multicolumn{2}{|l|}{ HPV } \\
\hline Positive & $15(100 \%)$ \\
\hline Negative & 0 \\
\hline \multicolumn{2}{|l|}{ Screened prior to HPV test screening } \\
\hline No & $12(80 \%)$ \\
\hline Yes & $3(20 \%)$ \\
\hline \multicolumn{2}{|l|}{$\begin{array}{l}\text { Attendance follow-up screening (14 months } \\
\text { past rapid HPV test) }\end{array}$} \\
\hline $\begin{array}{l}\text { Attended on scheduled appointment } \\
\text { date }\end{array}$ & $2(13 \%)$ \\
\hline $\begin{array}{l}\text { Attended between } 7 \text { and } 120 \text { days of } \\
\text { scheduled appointment }\end{array}$ & $4(27 \%)$ \\
\hline Did not attend scheduled appointmen & $9(60 \%)$ \\
\hline
\end{tabular}

The nurses agreed that many women come for screening when they have an urging health concern,

Most of the clients [...] have problems forcing them to come. One of the problems is infertility. They say they want to go through cancer screening but they don't have children. That is why they come for screening $[\ldots]$. Others come here because they have 
referral letters. [...] Some complain about lower abdominal pain. (Sister Victoria)

\section{Preventive health behaviour}

Awareness of cervical cancer and the possibility of preventing oneself from getting sick was another major reason for prioritising to go for screening,

I went for screening [...] just for check-up. I did not have any symptoms. [...] Awareness is increasing. I see more women going to the hospital even if they have no symptoms. (Irene)

Mona Lisa described her reflections this way,

I wanted to know my health. [...] I thought it is better to come early for screening despite the fact that I didn't have any symptoms, so that I could get treated early in case I had a problem. (Mona Lisa)

When discussing the reasons for going, it was clear that the benefits of coming had to be balanced against the challenges, which screening also entailed.

\section{Perceived costs of screening}

All women outlined a number of costs, which they personally experienced or expected others to have, when deciding whether or not to go for screening. This cost-benefit dilemma was present both when having to decide to go for the patient-initiated and health provider-initiated screening. However, often the challenges of returning for health provider-initiated follow-up screening outweighed the benefits of going, partly due to the screening only entailing the potential benefit of prevention. And partly due to a repeated gynaecological examination and the challenging label of being HPV-positive.

\section{Emotional costs due to fear of the examination}

The gynaecological examination was an element that several women described as a factor that prevented them from returning to screening. Grace said that,

I think they [ed. women] do not come back because of the nature of the screening itself-the gynaecological examination. It scares them off and it can be painful at times. I am one of the people who are also afraid. I really wanted to go back but when I thought about the gynaecological examination, I said "now I'm not going back'. (Grace)

A few women thought the examination entailed that the cervix was pulled outside the body during the examination, which frightened them,

The process [ed. examination] was improper as it involved pulling out, squeezing, the cervix. Pulling out or squeezing the cervix really hurts. There is pain. (Jacklen)

In contrast, several women described the examination as 'just fine' (Happy/Editha), and most stated that they felt the nurses treated them really good despite the examination being somewhat uncomfortable. The nurses supported the women's statements that fear of the examination kept some away. But they also experienced that most women talked to them about their concerns,

[...] some of them have the fear, but many appreciate the examination-'oh, I thought it was going to be painful, but it was not painful'. (Sister Lucky)

\section{Emotional costs due to fear of disease}

Cervical cancer was perceived as a dangerous disease that was linked to 'death' and several women described that it was 'worse than HIV' (Grace/Irene/Editha). Glory said that,

In case the results are bad, it is like the end of life. There is nothing to do. If you have cancer, then you are going to die. (Glory)

Despite numerous women stating that they went for an initial screening for preventive reasons it appeared thatcontrary to what was expected-the preventive nature often vanished once the women found themselves in the grey zone of being HPV-positive-having an increased risk but still not a patient with cancer. The label of being HPV-positive seemed difficult to comprehend and some feared they would be diagnosed with cancer if they returned,

They [ed. women] are afraid that if they come for check-up they will be found to have the disease. [...] It is said that cancer is more worse than HIV/AIDS. So that means when you have cancer you are dead. (Editha)

Others interpreted the label 'HPV-positive' as being 'fine' and 'not sick enough', hence they prioritised more urgent needs in their daily lives,

Initially, I was very worried. When the nurses told me, they were coming to see me I thought that I already have cancer. [...] They [...] told me that I am HPVpositive, but it doesn't mean I have cancer. [...] So, I was supposed to come back for check-up [...] but I didn't come. [...] I know that I still have the infection and I would like to come, but [...] family and economic problems, including not being able to afford transport to the clinic, made me not attend the clinic. (Gladness)

Both fear and other competing challenges were elements the nurses also outlined,

They don't like to come because of the fear of HPV, because they think when they are found to be HPVpositive that will be the end of their life. 'I don't want to hear again about HPV. I want to forget about it.' That is what they think. [...] Others they cannot come because they live far from their site of screening. But also, some of them they don't have money for transport to come for screening. (Sister Lucky) 


\section{Box 1 Catherine's story}

Today we visited Catherine who had not come for her check-up appointment. She was [...] wearing a blue scarf and we could hear the chickens outside while sitting on the floor of her living room when she told us her story. (Field note, first author)

\section{Catherine:}

Before I went for the screening I had certain symptoms - like [... ] heavy [...] menstrual blood during periods. And also, I had irregular periods. [...] And when I had sexual intercourse I had pain [...] [and] a lot of blood came out. That is why I decided to go for check-up at Ocean Road. When I went for the check-up I was found to have a tumour in my cervix. [...] So, Ocean Road took a biopsy to make sure whether it was cancer or not. After 1 week, they called me to go for my results. [...] On that day when I went for the results I was very worried. And during the week of waiting for the results I was very worried and totally sick. So, when they told me that my results are good (ed. the tumour was not cancer) (...) I was very happy. The happiest lady in the world. After 2 days I had a surgery and the surgery was successful [ed. the tumour was removed]. [...] I went back to Ocean Road twice [ed. for post surgery check-up]. Sister Victoria is the one who screened me. She told me 'now you are fine, you can bear a child. [Ed. at this last post-surgery screening she tested positive for HPV and was given a follow-up appointment 14 months later].

I was supposed to come back in April. [...] I saw it, but I had no time. [...] There is something surrounding me making me not to come back. But I want to come back! [It] is because of the hard-economic situation. Women are now running searching for food. People are running selling vegetable, selling... so that they can get something to eat. But when they find themselves sick, they will go back to for check-up. I'm just feeling good, I will go next week [...]. You see, we Tanzanians, when we are healthy we won't come back. .

Further, it appeared that whereas some women had a good understanding of HPV, others had not understood that they had tested HPV-positive and what that meant. While Mona Lisa said that 'I have HPV virus that causes cervical cancer' (Mona Lisa), Irene stated that, 'I don't know if I [am] HPV-positive' (Irene). Jacklen had expected to receive medicine when testing HPV-positive,

I have been told by a nurse [...] I [am] found to have HPV infection [...]. What kind of medication am I going to receive? Because I didn't [ed. receive any medication]. (Jacklen)

\section{Direct economic costs}

Despite the screening being cost free, related economic costs delayed or kept women from returning. Irene outlined her tough priorities this way,

Sometimes I don't have the money for transport. It is like, 'ah, I only have 2000 shillings [ed. less than USD 1] - should I use it to go to the hospital or buy food for the children?'. (Irene)

On top of the costs of transport, the screening also meant that income was lost the day they went (box 1). Jacklen put it this way,
If I go for examination now I will not be able to go sell my fish. (Jacklen)

\section{Indirect economic costs}

Apart from the direct economic cost, other indirect costs such as time spent accessing the clinic and the waiting time at the clinic were contributing factors to why returning for a screening was not a top priority. Catherine described it this way,

There is a certain number of patients served per day. It is twenty per day. So, if you are late you will not get any service, they will ask you to return the following day. I have responsibilities (and) I want to go for screening. But I am afraid that if I arrive there late all the numbers will be already gone and [I] will be asked to come the next day. (Catherine)

Editha perceived the issue as such,

Others come from upcountry and they come here for screening the first time but they find it difficult to return. [...] When you come back tomorrow you will find another huge crowd. (Editha)

\section{DISCUSSION}

This study shows that health provider-initiated follow-up cervical cancer screening attendance among Tanzanian HPV-positive women is a complex phenomenon, which is challenged by competing concerns. Motivating factors for patient-initiated screening involve treatment of gynaecological symptoms and prevention of disease. However, the key element of a health provider-initiated follow-up screening is prevention, which can be seen as a 'potential benefit' as a long as the woman is healthy. Hence, this can be postponed when other more immediate concerns overshadow this need. Challenges that prevent or delay women from returning include emotional and economic costs, such as the difficult label of being HPV-positive, fear of the gynaecological examination, loss of time and transport costs.

The screening dilemma found in this study can be conceptualised as a theoretical screening attendance model (figure 2). The model shows how screening attendance is an action, where women have to account for both the costs and benefits of going. While the same costs are present for both patient-initiated and health provider-initiated screening, the health provider-initiated follow-up screening is challenged by the circumstance that it only contains the potential benefit of prevention. The terms 'costs' and 'benefits' are inspired by health economic cost-benefit theory. ${ }^{31}$ However, in this model they are used as general concepts and not as quantifiable measures. As this model is developed based on these study findings alone, future studies may test the validity of the model.

To our knowledge, this is the first study in Africa where HPV-positive women have been followed up and asked 


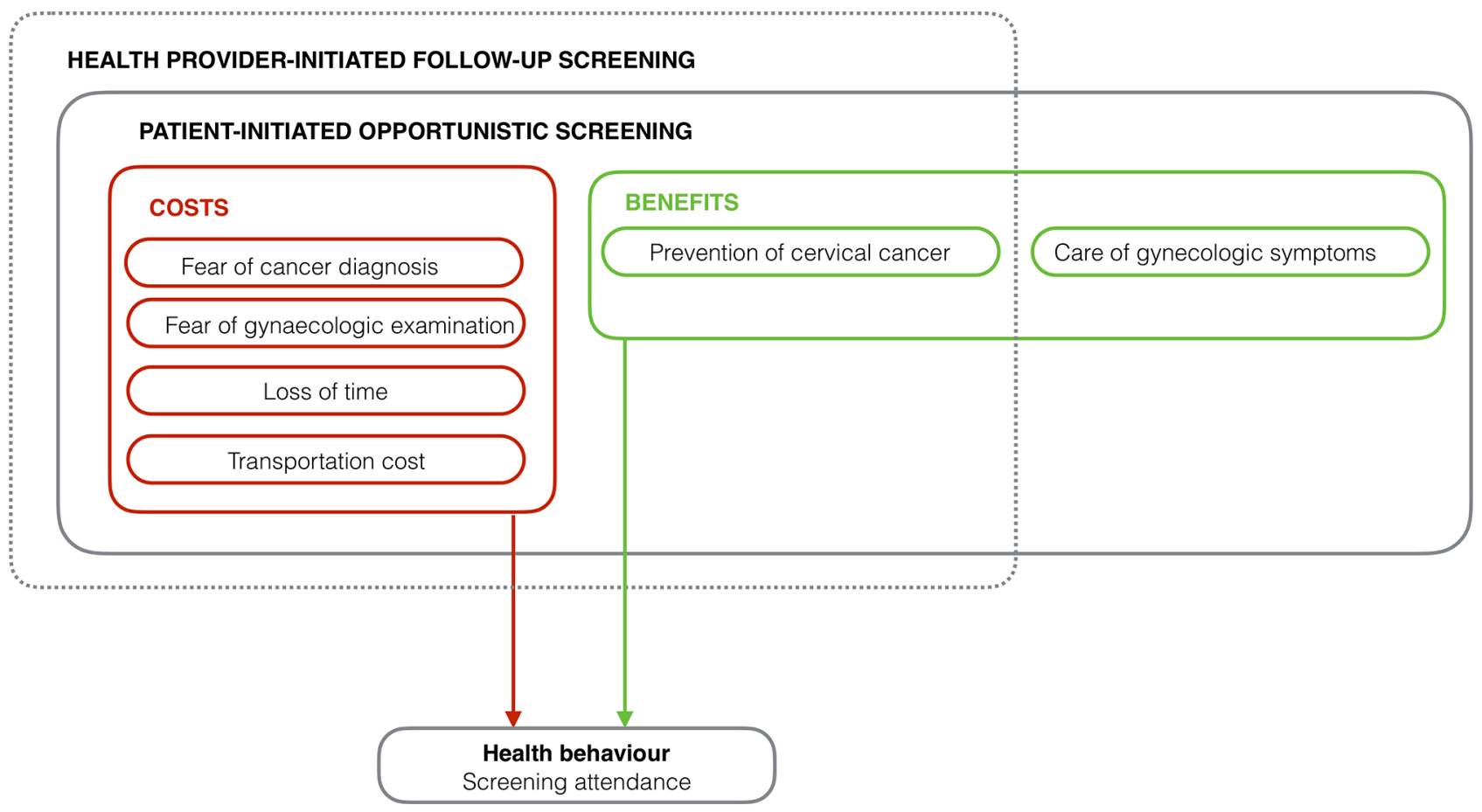

Figure 2 Screening attendance model.

for their reasons for attending a health provider-initiated follow-up appointment or not. Therefore, the comparability of the study results is somewhat limited. When comparing our results to a study for Nigeria that concerns default of follow-up for VIA, the results are moderately comparable. Similar to our study, the Nigerian study finds financial and time constrains as reasons for defaulting a follow-up appointment; however, it does not document emotional costs. ${ }^{20}$ When comparing our findings to studies that focus on facilitators and barriers of screening uptake, we see that in line with our study, a South African study documents the presence of gynaecological symptoms as an important reason for patient-initiated screening. However, it also documents the fear of having a HIV-test at the same time as the Pap smear and low support from peers as potential access barriers, which we did not find in this study. ${ }^{19}$ Similar to our study, other studies also report both emotional and economic barriers for screening uptake ${ }^{11} 13-17$ as well as women prioritising more contending needs when feeling healthy. ${ }^{17}$ Yet, they also report factors that influence uptake, which was not documented by this study, such as husband's approval. ${ }^{11} 1415$ It is plausible that facilitators and barriers for patient-initiated screening and health provider-initiated follow-up screening somewhat overlap. However, further research is needed to confirm this.

\section{Limitations}

This study reflects perceptions among screening nurses and HPV-positive women in Dar es Salaam and may show only one fraction of the complex picture of what affects screening follow-up behaviour among HPV-positive women. Eligible participants included screening nurses and women who had not attended, had delayed attendance or timely attended a follow-up screening. Despite the fact that data collection stopping when saturation was reached, it is plausible that a more nuanced view would have appeared if eligible participants had been limited to one of these groups. However, recruitment was difficult, and we experienced that both attending and non-attending clients shared many considerations.

\section{Lessons learnt}

This qualitative study is part of larger complex intervention study called Connected2Care that aims to increase the number of HPV-positive women that returns for follow-up cervical cancer screening and understand the underlying causes of cervical cancer screening behaviour. Together with the overall Connected2Care project, this qualitative study may help guide future complex interventions and screening programmes that involves HPV-testing in an African setting. Key elements that are identified in this substudy include perceived obstacles for returning for screening, such as fear of gynaecological examination, loss of time and transportation costs. If these findings are confirmed by other large-scale studies, future screening programmes could try to address these obstacles, for example, by conducting the follow-up screening as part of an outreach service with self-sample HPV test.

\section{CONCLUSION}

Tanzanian women's lives are filled with tough priorities, and in this context of competing obligations and concerns, attending to one's own personal health may not always be the top priority. This qualitative paper has 
documented that the status as 'HPV-positive' is a difficult label, and that the key element of a health provider-initiated follow-up screening is 'prevention', which can be postponed when other more immediate concerns are present. The potential benefit of prevention does not necessarily outweigh the emotional and economic cost of attending a follow-up screening.

Acknowledgements The authors would like to thank the participants of the study for sharing their personal views and experiences and for giving us insights into the many considerations Tanzanian women have in relation to cervical cancer screening. Also, we are grateful to ORCl's social worker, Devotha Kovaga, for getting in contact with the participants and for taking on the tough task of simultaneously translating the interviews. Finally, the authors would like to thank Danish International Development Agency (Danida), Danish Fellowship Centre (DFC) and the University of Southern Denmark for financing this study.

Contributors DSL conducted the interviews, drafted the manuscript and contributed to conceptualising and designing the study. VR, TMG and JDM contributed to conceptualising and designing the study and critically revised the manuscript. All authors approved the final manuscript.

Funding The study is funded by the Danish Ministry of Foreign Affairs through Danish International Development Agency (Danida), Danish Fellowship Centre (DFC) and the University of Southern Denmark.

Competing interests None declared.

Patient consent for publication Obtained.

Ethics approval Ethical clearance for the overall CONCEPT study was obtained from the National Institute for Medical Research in Tanzania for all study sites.

Provenance and peer review Not commissioned; externally peer reviewed.

Data sharing statement Additional unpublished data concerning perceptions of the SMS intervention are available. This includes interview data nurses and screening clients and focus group data with outreach nurses who perform home visits to HPV-positive clients informing them of their HPV status. We aim to publish these findings in the future.

Open access This is an open access article distributed in accordance with the Creative Commons Attribution Non Commercial (CC BY-NC 4.0) license, which permits others to distribute, remix, adapt, build upon this work non-commercially, and license their derivative works on different terms, provided the original work is properly cited, appropriate credit is given, any changes made indicated, and the use is non-commercial. See: http://creativecommons.org/licenses/by-nc/4.0/.

\section{REFERENCES}

1. Torre LA, Bray F, Siegel RL, et al. Global cancer statistics, 2012. CA Cancer J Clin 2015;65:87-108.

2. World Health Organization. International Agency for Research on Cancer. Cancer Fact Sheets: Cervical Cancer France: World Health Organization, 2012.

3. Fokom-Domgue J, Combescure C, Fokom-Defo V, et al. Performance of alternative strategies for primary cervical cancer screening in subSaharan Africa: systematic review and meta-analysis of diagnostic test accuracy studies. BMJ 2015;351:h3084.

4. Dartell M, Rasch V, Kahesa C, et al. Human papillomavirus prevalence and type distribution in 3603 HIV-positive and HIVnegative women in the general population of Tanzania: the PROTECT study. Sex Transm Dis 2012;39:201-8.

5. Kahesa C, Kjaer S, Mwaiselage J, et al. Determinants of acceptance of cervical cancer screening in Dar es Salaam, Tanzania. BMC Public Health 2012;12:1093.

6. Finocchario-Kessler S, Wexler C, Maloba M, et al. Cervical cancer prevention and treatment research in Africa: a systematic review from a public health perspective. BMC Womens Health 2016;16:29.

7. Modibbo F, Iregbu KC, Okuma J, et al. Randomized trial evaluating self-sampling for HPV DNA based tests for cervical cancer screening in Nigeria. Infect Agent Cancer 2017:12:11.

8. Organization WH. WHO guidelines for screening and treatment of precancerous lesions for cervical cancer prevention. Geneva: World Health Organization, 2013.
9. Linde DS, Andersen MS, Mwaiselage JD, et al. Text messages to increase attendance to follow-up cervical cancer screening appointments among HPV-positive Tanzanian women (Connected2Care): study protocol for a randomised controlled trial. Trials 2017;18:555.

10. Osingada CP, Ninsiima G, Chalo RN, et al. Determinants of Uptake of Cervical Cancer Screening Services at a No-cost Reproductive Health Clinic Managed by Nurse-Midwives. Cancer Nurs 2015;38:177-84.

11. Lyimo FS, Beran TN. Demographic, knowledge, attitudinal, and accessibility factors associated with uptake of cervical cancer screening among women in a rural district of Tanzania: three public policy implications. BMC Public Health 2012;12:22.

12. Morema EN, Atieli HE, Onyango RO, et al. Determinants of cervical screening services uptake among 18-49 year old women seeking services at the Jaramogi Oginga Odinga Teaching and Referral Hospital, Kisumu, Kenya. BMC Health Serv Res 2014;14:335.

13. Aweke YH, Ayanto SY, Ersado TL. Knowledge, attitude and practice for cervical cancer prevention and control among women of childbearing age in Hossana Town, Hadiya zone, Southern Ethiopia: Community-based cross-sectional study. PLoS One 2017;12:e0181415.

14. Isa Modibbo F, Dareng E, Bamisaye P, et al. Qualitative study of barriers to cervical cancer screening among Nigerian women. BMJ Open 2016;6:e008533.

15. Ndejjo R, Mukama T, Kiguli J, et al. Knowledge, facilitators and barriers to cervical cancer screening among women in Uganda: a qualitative study. BMJ Open 2017;7:e016282.

16. Eleanor Chadza EC, Maluwa A, Malata A, et al. Factors that contribute to delay in seeking cervical cancer diagnosis and treatment among women in Malawi. Scientific Research 2012;4:1015-22.

17. Ndikom CM, Ofi BA. Awareness, perception and factors affecting utilization of cervical cancer screening services among women in Ibadan, Nigeria: a qualitative study. Reprod Health 2012;9:11.

18. Knegt $Y$. Audit of cervical cancer screening and colposcopy attendance in rural South Africa. Afr J Reprod Health 2014;18:70-8

19. Momberg M, Botha MH, Van der Merwe FH, et al. Women's experiences with cervical cancer screening in a colposcopy referral clinic in Cape Town, South Africa: a qualitative analysis. BMJ Open 2017;7:e013914.

20. Ezechi OC, Petterson KO, Gbajabiamila TA, et al. Predictors of default from follow-up care in a cervical cancer screening program using direct visual inspection in south-western Nigeria. BMC Health Serv Res 2014;14:143.

21. Smillie K, Van Borek N, Abaki J, et al. A qualitative study investigating the use of a mobile phone short message service designed to improve HIV adherence and retention in care in Canada (WelTel BC1). $J$ Assoc Nurses AIDS Care 2014;25:614-25.

22. Smillie K, Van Borek N, van der Kop ML, et al. Mobile health for early retention in HIV care: a qualitative study in Kenya (WelTel Retain). Afr J AIDS Res 2014;13:331-8.

23. Carrillo JE, Carrillo VA, Perez HR, et al. Defining and targeting health care access barriers. $J$ Health Care Poor Underserved 2011;22:562-75

24. Ajzen I. The theory of planned behavior. Organ Behav Hum Decis Process 1991;50:179-211.

25. Davis FD, Bagozzi RP, Warshaw PR. User acceptance of computer technology: a comparison of two theoretical models. Manage Sci 1989;35:982-1003.

26. Glaser BG SA. The discovery of groundhed theory. strategies for qualiative research. United States of America: AldineTransaction 1967, 1999

27. Kvale S. Doing interview: Sage, 2007.

28. Schreier M. Qualitative content analysis in practice. London: Sage, 2013.

29. Students of the World. Top 100 Tanzanian names - Tanzania: France. $2001 \mathrm{http} / / / w w w . s t u d e n t s o f t h e w o r l d . i n f o / p e n p a l s / s t a t s . p h p 3 ? P a y s=$ TZA (accessed 15 Mar 2018).

30. O'Brien BC, Harris IB, Beckman TJ, et al. Standards for reporting qualitative research: a synthesis of recommendations. Acad Med 2014;89:1245-51.

31. Michael Drummond F, Claxton K, Stoddart GL, et al. Methods for the economic evaluation of heatlh care programmes. Fourth ed. Oxford: Oxford University Press, 2015.

32. Central Intelligence Agency. The World Factbook. Africa: Tanzania: Central Intelligence Agency, 2018. 